\title{
Mytilid mussels: global habitat engineers in coastal sediments
}

\author{
Christian Buschbaum • Sabine Dittmann · Jae-Sang Hong • In-Seo Hwang • \\ Matthias Strasser • Martin Thiel • Nelson Valdivia · San-Pil Yoon • \\ Karsten Reise
}

Received: 2 June 2008 / Revised: 6 August 2008 / Accepted: 7 August 2008 / Published online: 1 November 2008

(C) Springer-Verlag and AWI 2008

\begin{abstract}
Dense beds of mussels of the family Mytilidae occur worldwide on soft-bottoms in cold and warm temperate coastal waters and have usually been considered hot spots of biodiversity. We examined intertidal mussel beds at four distant locations around the globe with the same sampling method, to find out whether this "hot spot" designation holds universally. We studied species assemblages within the matrices of byssally interconnected mussels engineered by Mytilus edulis in the North Sea, by mixed Perumytilus purpuratus and Mytilus chilensis at the southern Chilean coast, by Musculista senhousia in the Yellow
\end{abstract}

Communicated by K. Reise.

C. Buschbaum $(\varangle) \cdot$ M. Strasser $\cdot$ K. Reise

Wadden Sea Station Sylt, Alfred Wegener Institute for Polar and Marine Research, Hafenstrasse 43, 25992 List, Germany e-mail: Christian.Buschbaum@awi.de

\section{S. Dittmann}

School of Biological Sciences, Flinders Universiy,

GPO Box 2100, Adelaide, SA 5001, Australia

J.-S. Hong · I.-S. Hwang · S.-P. Yoon

Department of Oceanography, Inha University,

Incheon 402-751, South Korea

\section{Thiel · N. Valdivia}

Facultad Ciencias del Mar, Universidad Católica del Norte, Larrondo 1281, Coquimbo, Chile

M. Thiel

Centre for Advanced Studies in Arid Systems,

CEAZA, Coquimbo, Chile

\section{N. Valdivia}

Biologische Anstalt Helgoland, Alfred Wegener Institute for Polar and Marine Research, Kurpromenade 201,

27498 Helgoland, Germany
Sea and by Xenostrobus inconstans at the coast of southern Australia. In all cases, species assemblages inside mussel beds were significantly different from those outside with many species being restricted to one habitat type. However, species richness and diversity were not generally higher in mussel beds than in ambient sediments without mussels. In the North Sea (M. edulis) and at the Chilean coast (P. purpuratus, $M$. chilensis), mussel beds have markedly higher species numbers and diversities than surrounding sediments, but this was not the case for mussel beds in Australia (X. inconstans) and the Yellow Sea (M. senhousia) where numbers of associated species were only slightly higher and somewhat lower than in adjacent sediments, respectively. In conclusion, although soft bottom mytilid mussels generally enhance habitat heterogeneity and species diversity at the ecosystem level, mussel beds themselves are not universal centres of biodiversity, but the effects on associated species are site specific.

Keywords Ecosystem engineer - Mussel bed - Diversity · Species richness $\cdot$ Soft bottom

\section{Introduction}

Mytilid mussels occur on rocky and sedimentary coasts worldwide (Suchanek 1986). They tend to form dense aggregations by attaching byssal threads to the substratum and conspecifics. These persistent bioaggregates physically change the environment and create unique habitats (Gutiérrez et al. 2003). Therefore, according to the concept of Jones et al. (1994, 1997), mussels are considered ecosystem engineers (Crooks 2002; Gutiérrez et al. 2003). Beds of mytilid mussels are highly structured compared to surrounding areas (Fig. 1) and this entails a specific and 
Fig. 1 Mytilid mussels form beds on rocky and sedimentary shores. Soft bottom mussel beds may grade from epibenthic with most mussels lying upon the sediment surface to endobenthic with most individuals lodged in the sediment

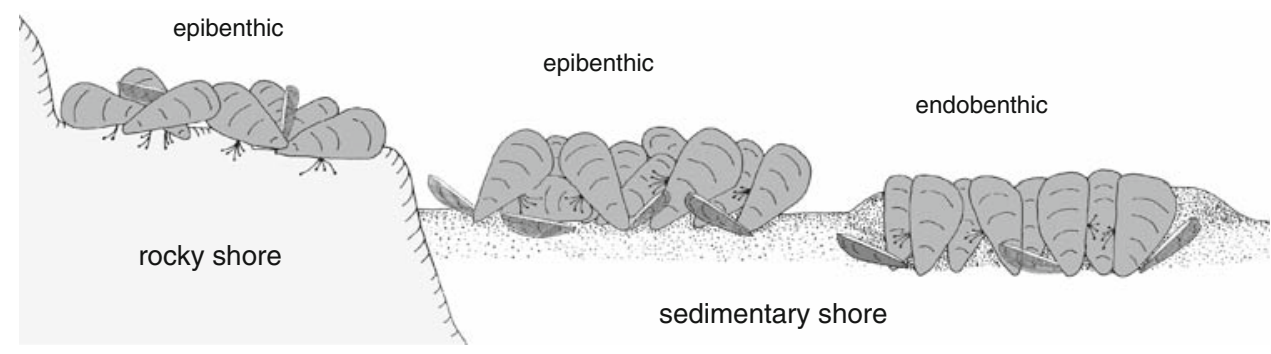

diverse associated species assemblage (e.g. Asmus 1987; Ong Che and Morton 1992; Seed and Suchanek 1992; Peake and Quinn 1993; Lintas and Seed 1994; Seed 1996; Smith et al. 2006; Büttger et al. 2008). Rocky shore mytilid mussel beds are considered biodiversity hot spots because they harbour communities that are generally more diverse than assemblages on surrounding rock without mussels. This pattern occurs in beds of Mytilus californianus Conrad on the Pacific coast of North America (Suchanek 1986, 1992), patches of Mytilus edulis L. in Japan (Tsuchiya and Nishihira 1985, 1986), aggregations of Perumytilus purpuratus Lamarck in Chile (Thiel and Ullrich 2002; Valdivia and Thiel 2006), beds of Semimytilus algosus (Gould) in central Peru (Tokeshi 1995; Tokeshi and Romero 1995) and mussel beds of Brachidontes rodriguezii (d'Orbigny), Mytilus edulis platensis (d'Orbigny) and Perna perna (L.) on the Atlantic coast of Uruguay (Borthagaray and Carranza 2007).

Species associated with beds of mytilid mussel on softbottoms have received less attention. On sedimentary coasts of the North Sea, Dittmann (1990), Günther (1996) and Ragnarsson and Raffaelli (1999) detected higher macrofaunal species richness in $M$. edulis beds than on surrounding flats. The same was true for soft bottom M. edulis beds on the west coast of Sweden (Norling and Kautsky 2007). These North Sea data were obtained from mainly epibenthic mussel beds in which the living individuals are positioned on the sediment surface or only slightly stuck in the mud.

While mussels on rocky surfaces are always epibenthic, soft bottom mussel beds may also be endobenthic, with a diversity of transitions between epibenthic and endobenthic mode (Fig. 1). In endobenthic beds, most individuals are positioned below the sediment surface and only the posterior end with the siphonal apertures projects above the surface (Albrecht and Reise 1994). Endobenthic mussel beds may also be inhabited by a rich associated assemblage of species. For example, on the US Pacific coast, the introduced mussel Musculista senhousia Benson in Cantor has facilitating effects on other organisms (Crooks 1998). Densities of macrofaunal individuals and species richness were higher inside than outside these mussel mats. However, studies performed by Commito (1987) and Commito et al.
(2005) on the US Atlantic coast revealed that semi-endobenthic beds of M. edulis may have species diversities that are similar or reduced in comparison to the surrounding sedimentary environment. This suggests that mussel aggregations in sedimentary environments may not invariably be diversity hot spots within the ecosystems in which they are found.

Therefore, we propose that the specific modes in which mussels provide hard substratum and shelter, stabilize, accrete and modify sediments and occupy space can have facilitatory on some as well as inhibitory effects on other species. Depending on the coastal system and its species assemblage these effects may result in either enhanced or decreased diversity within mussel beds. Independently of the richness of associated communities, mussel aggregations may provide habitat to species that are otherwise absent or rare in soft bottom habitats (Commito and Dankers 2001). Thus, we go on to propose that mussel beds generally increase biodiversity at the ecosystem level by enhancing habitat heterogeneity, while biodiversity within beds may not be necessarily higher than outside.

To explore these propositions we studied associated species assemblages of soft bottom mussel aggregations in comparison to the surrounding tidal flats without mussels in four coastal systems worldwide. We investigated epibenthic beds of the mussel M. edulis in the Northeast Atlantic (North Sea) and mixed aggregations of $P$. purpuratus and M. chilensis Hupe 1854 in the Southeast Pacific, while endobenthic beds of the bivalves M. senhousia and Xenostrobus inconstans (Dunker) were examined in the Northwest Pacific (Yellow Sea) and southern Indopacific, respectively.

\section{Materials and methods}

Mussel beds and study sites

Investigations of mussel beds of M. edulis and surrounding sand flats were conducted in the northern Wadden Sea near the island of Sylt $\left(54^{\circ} 55^{\prime} \mathrm{N}, 008^{\circ} 20^{\prime} \mathrm{E}\right)$ in the Northeast Atlantic (North Sea, German Bight) in August 2002 (Fig. 2). The study area belongs to the cold temperate 
Fig. 2 Study areas of mussel beds and surrounding intertidal sediments: epibenthic mussel beds were investigated in the Northeast Atlantic (North Sea, beds of Mytilus edulis, a) and in the Southeast Pacific (beds of Mytilus chilensis and Perumytilus purpuratus, b). Endobenthic mussel beds were studied in the West Pacific (Yellow Sea, beds of Musculista senhousia, c) and in the Indian Ocean (beds of Xenostrobus inconstans, $\mathbf{d}$ ). Study sites are marked by an arrow

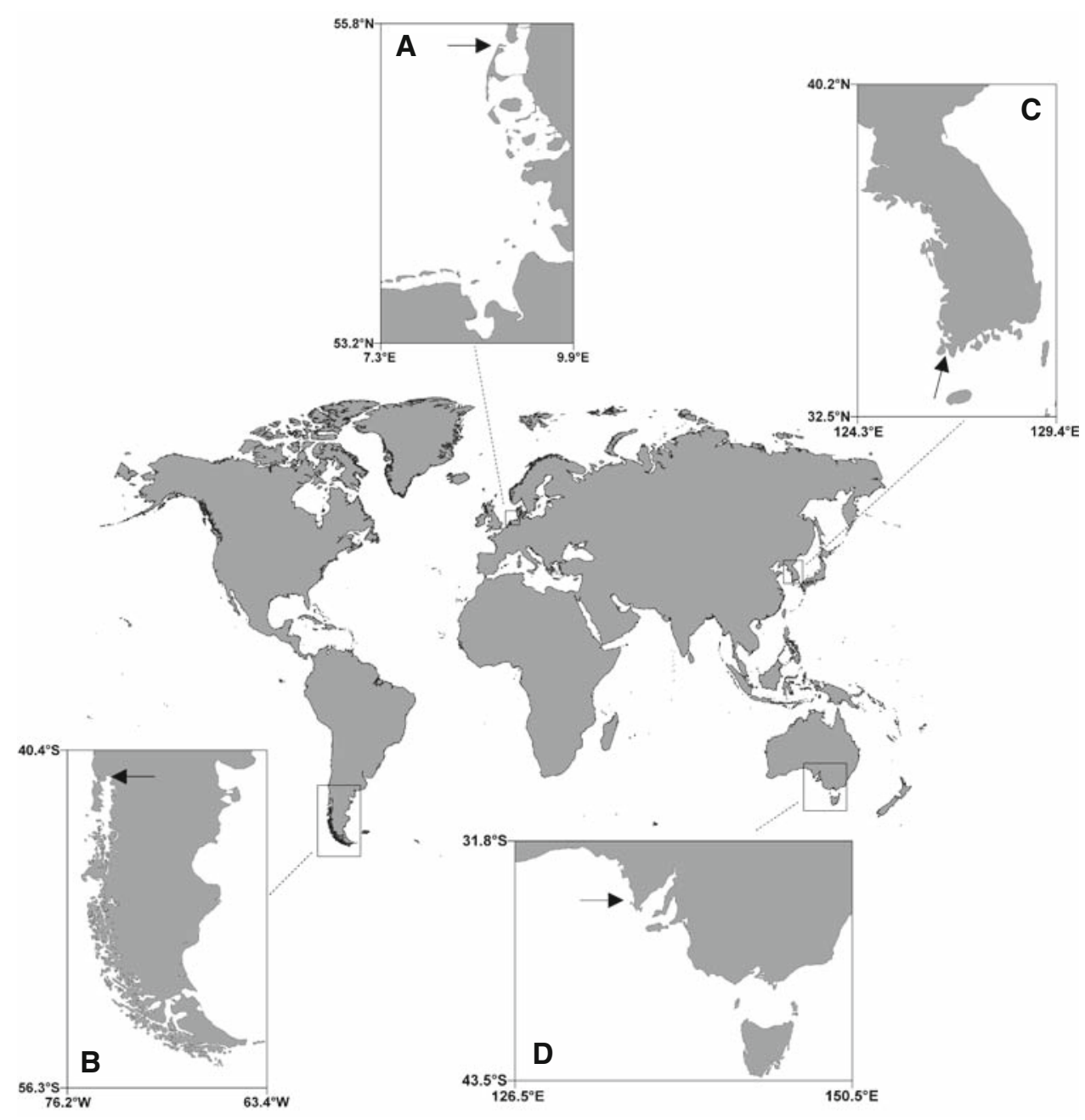

region with a mean annual water temperature of about $9^{\circ} \mathrm{C}$, a summer average of $15^{\circ} \mathrm{C}$, and a winter average of $4^{\circ} \mathrm{C}$. Tides are semi-diurnal (mean range of $2 \mathrm{~m}$ ) and salinity remains close to $30 \mathrm{psu}$. For further information on the area see Reise (1985) and Gätje and Reise (1998).

M. edulis is a common mytilid mussel of north European coastal systems where it occurs on both rocky and sedimentary shores (Seed and Suchanek 1992). In the intertidal zone of the northern Wadden Sea, M. edulis forms predominantly multi-layered beds on the sediment surface and may achieve densities of about 4,000 ind. $\mathrm{m}^{-2}$ (Buschbaum and Saier 2001). These are categorized as epibenthic because most living mussels dwell above the sediment surface.

In March 2003, we studied a second type of epibenthic mussel bed formed by the bivalves $M$. chilensis and $P$. purpuratus at Bahia Cohuin near Puerto Montt $\left(41^{\circ} 29^{\prime} \mathrm{S}\right.$, $072^{\circ} 52^{\prime} \mathrm{W}$ ), an intertidal soft bottom area in the fjord region of southern Chile, Southeast Pacific (Fig. 2). Here, the tidal range is close to $5 \mathrm{~m}$ (Duarte et al. 2006, Jaramillo et al. 2007). Water temperatures range from $12^{\circ} \mathrm{C}$ in winter to $26^{\circ} \mathrm{C}$ during the summer season (Gebauer et al. 2007).
Depending on rainfall, salinity ranges from 25 to $30 \mathrm{psu}$. In this coastal environment, mussel beds comprise $M$. chilensis and $P$. purpuratus. Mussel beds in the low intertidal zone are dominated by $M$. chilensis while those in the mid intertidal zone are dominated by $P$. purpuratus, which may contribute up to two-thirds of total mussel densities (about $3,500 \mathrm{~m}^{-2}$, M. Thiel, unpublished data). While the purple mussel $P$. purpuratus usually inhabits intertidal hard bottoms (Thiel and Ullrich 2002), in the fjord region it may also form dense aggregations on soft bottoms, similar to those reported for $M$. edulis.

On the west coast of South-Korea (Yellow Sea), about $60 \mathrm{~km}$ south of the city of Mokpo near Sanjong/Donghyeon $\left(34^{\circ} 21^{\prime} \mathrm{N}, 126^{\circ} 30^{\prime} \mathrm{E}\right)$ we investigated species richness and diversity in mussel aggregations formed by the bivalve M. senhousia and in the ambient tidal flats (Fig. 2). Tidal range is about $2.5 \mathrm{~m}$. Studies were done in July 2002. In this year water temperature ranged from $7^{\circ} \mathrm{C}$ in winter (February) to $25^{\circ} \mathrm{C}$ in summer (August) while salinity remained close to 32 psu the whole year round (J.-S. Hong, personal communication). 
Musculista senhousia is a comparatively small (maximum shell length up to $35 \mathrm{~mm}$ ) mytilid bivalve with a life span of less than 2 years (Morton 1974). As with other mytilid mussels, $M$. senhousia produces byssal threads and uses them to create byssal bags or cocoons. At high densities of $>1,500 \mathrm{~m}^{-2}$ it forms a mat on the bottom consisting of a matrix of empty bivalve shells, byssal threads and ambient sediment (Morton 1974, 1992; Crooks 1996; Reusch and Williams 1998). Mussel aggregations form hummocks on the bottom and individuals are lodged within the sediment and only a few individuals pop up at the surface. These mussel beds are categorized as endobenthic.

We investigated beds of $X$. inconstans in Kellidie Bay, a sedimentary bight within Coffin Bay on the southern shore of Australia $\left(34^{\circ} 37^{\prime} \mathrm{S}, 135^{\circ} 30^{\prime} \mathrm{E}\right.$, Indian Ocean) in January 2007 (Morton 1992; Dittmann 2007; Fig. 2). The tides in this area are considerably more irregular than in many parts of the world and only semi-diurnal at spring periods. Tidal range is about $2 \mathrm{~m}$, but may be greatly modified by winds. Mean seawater temperatures are about $19^{\circ} \mathrm{C}$ in summer (February) and $14^{\circ} \mathrm{C}$ during winter (August). During summer water temperatures of up to $30^{\circ} \mathrm{C}$ occur in shallow bays or inlets. General information on the hydrography, biota and ecology of south Australian coasts is available in Womersley and Edmonds (1958) and Edgar (2000). As with $M$. senhousia, most $X$. inconstans individuals were lodged within the sediment but they were more crowded, which pushed several individuals above the sediment surface. As these are still a minority, we categorize the Australian mussel beds as endobenthic.

\section{Sampling procedure}

All mussel beds and surrounding bare tidal flats without bivalves were sampled with exactly the same procedure to ensure homogeneity of the methods used at all study sites. Mussel beds had a size of $>10 \mathrm{~m}^{2}$ and were at least 2 years old. They were sampled using a corer of $10.5 \mathrm{~cm}$ diameter (corresponding to an area of $85 \mathrm{~cm}^{2}$ ). Previous investigations indicated that sample sizes between 50 and $200 \mathrm{~cm}^{2}$ provide representative estimates for species and individual numbers of organisms living associated with mussel beds (Günther 1996; Asmus 1987; Tsuchiya and Nishihira 1985; Commito and Boncavage 1989; Ragnarsson and Raffaelli 1999; Peake and Quinn 1993; Duarte et al. 2006).

The corer was inserted to a depth of $20 \mathrm{~cm}$ into the sediment. Then, the mussel mats on top of the samples were carefully separated from the sediment below and washed over a $0.5 \mathrm{~mm}$ sieve. Mussels were counted and their lengths measured (maximum anterior-posterior axis) to the nearest $1 \mathrm{~mm}$ using vernier callipers. Additionally, all epibionts (macroalgae and invertebrates) attached to the mussels and all mobile organisms remaining in the sieve were quantified and identified to the lowest taxonomic level possible.

The sediment sample was divided into two sub samples. The upper $5 \mathrm{~cm}$ sediment layer was sieved through a $0.5 \mathrm{~mm}$ mesh size, and a 1-mm sieve was used for the lower $15 \mathrm{~cm}$ sediment layer. This was done because most soft bottom organisms live in the upper $5 \mathrm{~cm}$ and individuals $<1 \mathrm{~mm}$ seldom occur in deeper sediment layers. All live organisms retained in the sieves were counted and identified to the lowest taxonomic level possible.

We classify the associated community into epibiotic species (sessile species that were attached to mussels), epibenthic organisms (mobile species living on the sediment surface and between the mussels) and endobenthic species (living below the sediment surface). These are the three characteristic categories of organisms comprising a mussel bed association (Suchanek 1986; Lintas and Seed 1994).

Samples of the sedimentary areas around mussel beds were taken and handled in the same way. However, as there were no mussels in these samples, no epibenthic layer was treated separately. In all areas investigated we collected 12 mussel bed samples and 12 samples from surrounding tidal flats, respectively. At each study site, samples were haphazardly taken from several mussel beds located in the lower tidal zone and from a large area $(1,000 \times 1,000 \mathrm{~m})$ of surrounding tidal flats consisting of sandy sediments.

\section{Statistical analyses}

Data are presented as arithmetic means with standard deviation (SD). Mussel density differences between mussel beds formed by different mytilid species were tested by a Kruskal-Wallis $H$ test (Kruskal-Wallis ANOVA), followed by pairwise Mann-Whitney $U$ tests. We analysed mean species number differences inside and outside the mussel beds with $t$ tests. $F$ tests were used to test for homoscedasticity of variances, and dependent variables were $\log (x+1)$-transformed when variances were heterogenous. Results were considered statistically significant at $P \leq 0.05$ and the Bonferroni correction was applied to multiple comparisons.

Entire communities of mussel beds and surrounding sedimentary areas of the respective study sites were analysed using multivariate, non-parametric ordination techniques including multidimensional scaling (MDS) and analysis of similarities (ANOSIM) based on the Bray-Curtis similarity comparisons in the PRIMER ${ }^{\mathrm{TM}}$ software package (Clarke and Warwick 2001). Multivariate analyses were performed on square root transformed data. The PRIMER ${ }^{\mathrm{TM}}$ software package was also used for preparing species-sample/area plots. For comparison of species assemblages, two indices were calculated: (1) Shannon Wiener Index $H=-\sum p_{i} \ln p_{i}$, where $p_{i}$ is the proportion of the total number of individuals 
$(N)$ made up by specimens of $\operatorname{species}_{i}\left(n_{i}\right): p_{i}=n_{i} / N$, and (2) Evenness $e=H / \ln S$, where $S$ is the total number of species.

\section{Results}

Mussel bed characteristics

Mussel size-frequency distribution differed among mussel beds (Fig. 3). Epibenthic beds of M. edulis in the Wadden Sea had a wide size distribution of individuals ranging from 5 to $60 \mathrm{~mm}$ lacking conspicuous modes. In epibenthic beds consisting of $P$. purpuratus and $M$. chilensis in Chile, most mussels occurred within the size range from 20 to $43 \mathrm{~mm}$ with a strong peak around $30 \mathrm{~mm}$.

The size-frequency distribution of endobenthic beds of M. senhousia in South-Korea ranged only from 5 to $19 \mathrm{~mm}$ and was almost uni-modal, with a peak close to $12 \mathrm{~mm}$. Shell lengths of $X$. inconstans forming endobenthic mussel beds in Australia ranged from 1 to $28 \mathrm{~mm}$ and the size-frequency distribution shows two strong modes, with peak frequencies near 8 and $21 \mathrm{~mm}$.

Mussel densities in beds formed by different mytilid species were significantly different (Kruskal-Wallis $H$ test, $P<0.0001, n=12$ ), and differed significantly from each other (Mann-Whitney $U$ test, $P<0.002$, Bonferroni corrected level of significance $P<0.008, n=12$ ), except for Wadden Sea M. edulis $\left(1,871 \pm 751\right.$ ind. $\left.\mathrm{m}^{-2}\right)$ and South Korean $M$. senhousia $\left(1,927 \pm 718\right.$ ind. $\left.\mathrm{m}^{-2}\right)$. Highest mussel density occurred in beds of $X$. inconstans in Australia $\left(18,393 \pm 5,831\right.$ ind. $\left.\mathrm{m}^{-2}\right)$ while abundances in mussel beds of $P$. purpuratus and $M$. chilensis were intermediate

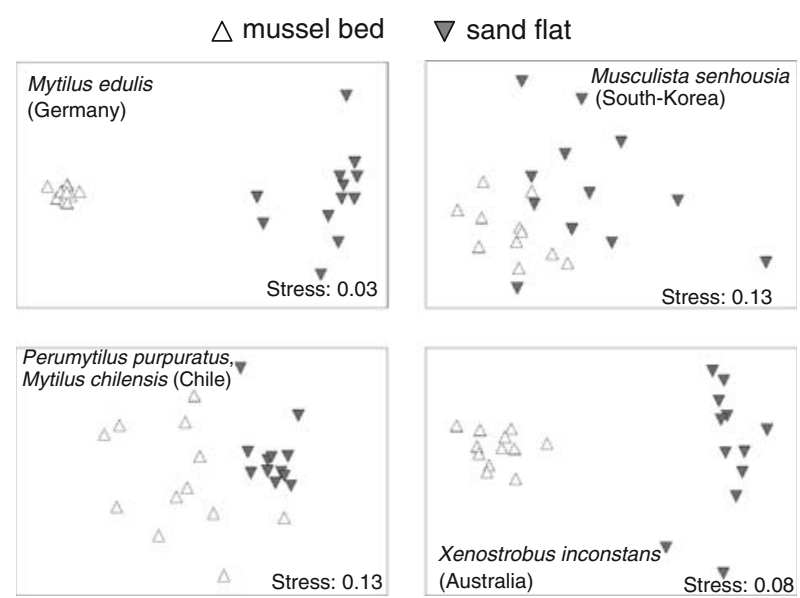

Fig. 4 Multidimensional scaling (MDS) ordination plots of species communities inside and outside mussel beds in four regions of the world (see Fig. 2). Analyses are based on Bray-Curtis similarities using abundance data of species

(total abundance $3,442 \pm 515$ ind. $\mathrm{m}^{-2} ; \quad P$. purpuratus $2,380 \pm 741$ ind. $\mathrm{m}^{-2}$, M. chilensis $1,062 \pm 511$ ind. $\mathrm{m}^{-2}$ ) on the Chilean coast.

\section{Community analyses}

The species communities inside and outside of mussel beds were significantly different in the four coastal systems (Fig. 4). The ANOSIM procedure calculated an $R$-statistic of $0.997(P<0.001)$ for differences among communities of mussel beds (M. edulis) and sand flats in the North Sea (Germany) and an $R$-statistic of $0.507(P<0.001)$ for differences among assemblages of mussel aggregations
Fig. 3 Pooled shell length data for all samples of mussels Mytilus edulis in the Northeast Atlantic (Germany), Perumytilus purpuratus and Mytilus chilensis in the Southeast Pacific (Chile) and beds of Musculista senhousia in the Yellow Sea (SouthKorea) and of Xenostrobus inconstans in the Indian Ocean (Australia). Sample size was $85 \mathrm{~cm}^{2}(n=12$ samples per area)
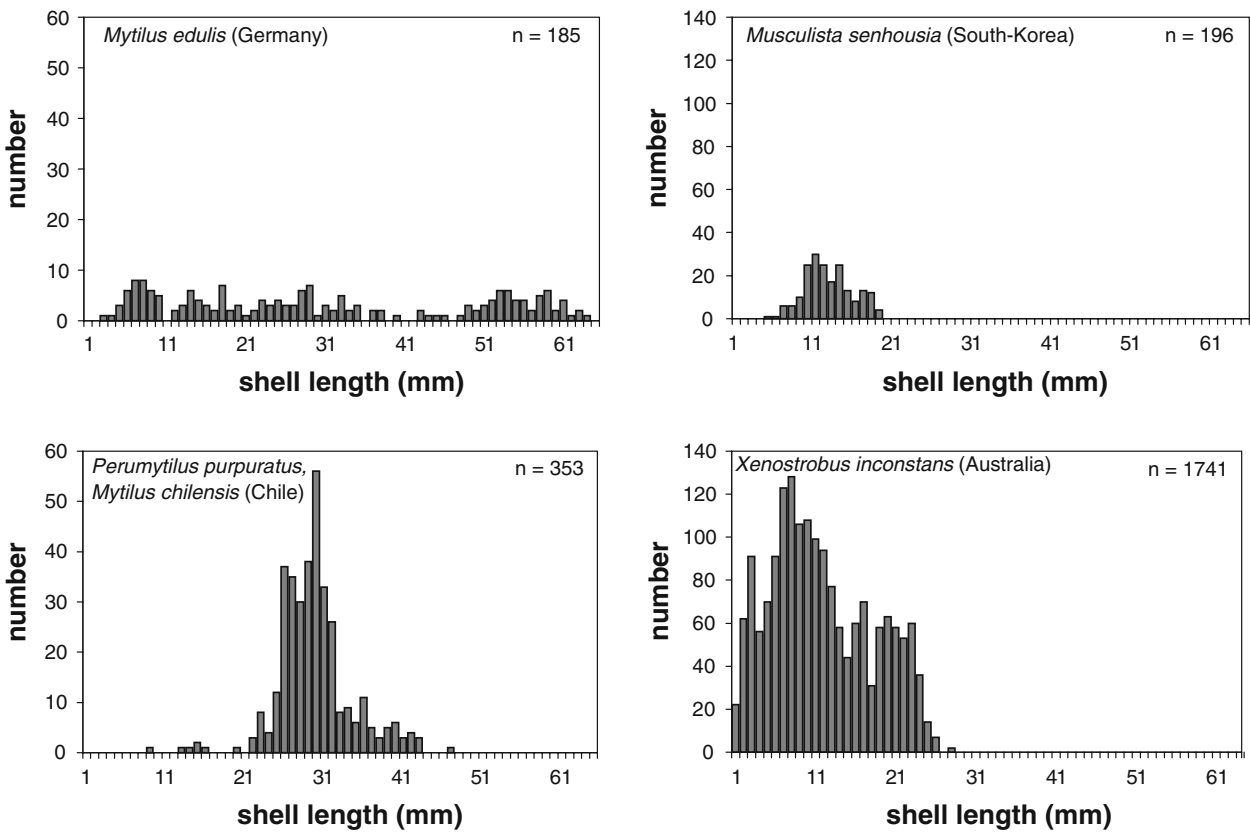
(P. purpuratus and M. chilensis) and surrounding bare areas at the Chilean coast. Communities of mussel beds of M. senhousia $(R=0.333)$ and $X$. inconstans $(R=0.987)$ were also significantly different from assemblages inhabiting tidal flats without mussels ( $P<0.001$, respectively).

The Shannon Wiener Index $H$ was higher in mussel beds in the North Sea, Chilean and south Australian coasts, but lower in the Yellow Sea in comparison to sediments without mussels (Table 1). Evenness was higher in mussel beds in the North Sea and on the south Australian coast, but lower at the Chilean coast and in the Yellow Sea compared to surrounding sediments. At all study sites, percentage of species found only in mussel beds was at least $30 \%$, and reached $59 \%$ in beds of $M$. edulis in the North Sea (Table 2). Crustaceans, molluscs and polychaetes were the main taxanomic groups in both mussel beds and sand flats in all investigated areas (Table 3).

\section{Associated species richness}

In both epibenthic mussel beds of $M$. edulis (Germany) and mixed beds of $P$. purpuratus and $M$. chilensis (Chile), total species number was about double that in surrounding sand flats (Fig. 5). In endobenthic mussel beds, the pattern was not as clear cut as in epibenthic mussel aggregations. Beds of M. senhousia in South-Korea had reduced species numbers in comparison to the bare tidal flat (Fig. 5). In contrast, species richness of $X$. inconstans beds (Australia) was slightly higher inside mussel aggregations than outside.

Species-sample curves of the sites had similar shapes, reaching asymptotes (Fig. 5). This indicates that the respective species communities are representatively sampled and an increase in sampling effort would not have changed results.

The mean species number in mussel beds and surrounding sand flats fitted the pattern for total species number (Fig. 6). In North Sea M. edulis beds, mean species number (16.6 \pm 2.1 species per sample) was significantly higher $(t$ test, $P<0.0001)$ than in areas without mussels $(5.1 \pm 1.3$ species per sample). In Chilean mixed beds of $P$. purpuratus and $M$. chilensis mean species number in mussel aggregations $(11.0 \pm 1.3$ species per sample $)$ was also significantly higher ( $t$ test, $P<0.0001)$ than on bare tidal flats $(7.9 \pm 1.2$ species per sample $)$.

Table 1 Shannon Wiener Index $H$ and evenness $e$ in mussel beds and surrounding sediments without mussels of the respective study sites

\begin{tabular}{|c|c|c|c|c|c|c|c|c|}
\hline & \multicolumn{2}{|l|}{ North Sea } & \multicolumn{2}{|c|}{ Chilean coast } & \multicolumn{2}{|l|}{ Yellow Sea } & \multicolumn{2}{|c|}{ South Australian coast } \\
\hline & Mussel bed & Sand flat & Mussel bed & Sand flat & Mussel bed & Sand flat & Mussel bed & Sand flat \\
\hline Shannon Wiener $H$ & 1.84 & 1.06 & 2.14 & 1.74 & 1.70 & 2.67 & 2.31 & 1.52 \\
\hline Evenness $e$ & 0.53 & 0.38 & 0.69 & 0.70 & 0.63 & 0.90 & 0.67 & 0.47 \\
\hline
\end{tabular}

Table 2 Total number of species, species number detected in only one habitat and number of species occurring in both mussel beds and sand flats in the study sites

\begin{tabular}{lcccc}
\hline & North Sea & Chilean coast & Yellow Sea & South Australian coast \\
\hline Total no. of species & 41 & 25 & 29 & 42 \\
No. of species restricted to mussel beds & $24(59 \%)$ & $13(52 \%)$ & $9(31 \%)$ & $16(38 \%)$ \\
No. of species restricted to sand flats & $9(22 \%)$ & $2(8 \%)$ & $14(48 \%)$ & $10(24 \%)$ \\
No. of species occurring in both habitats & $8(19 \%)$ & $10(40 \%)$ & $6(21 \%)$ & $16(38 \%)$ \\
\hline
\end{tabular}

Numbers of epibiotic, epibenthic and endobenthic species within the dominant taxa are given in parentheses (epibionts/epibenthos/endobenthos)

Table 3 Species number of dominant taxa in mussel beds and surrounding sediments

\begin{tabular}{|c|c|c|c|c|c|c|c|c|}
\hline & \multicolumn{2}{|l|}{ North Sea } & \multicolumn{2}{|c|}{ Chilean coast } & \multicolumn{2}{|l|}{ Yellow Sea } & \multicolumn{2}{|c|}{ South Australian coast } \\
\hline & Mussel bed & Sand flat & Mussel bed & Sand flat & Mussel bed & Sand flat & Mussel bed & Sand flat \\
\hline Algae & $4(4 / 0 / 0)$ & $0(0 / 0 / 0)$ & $0(0 / 0 / 0)$ & $0(0 / 0 / 0)$ & $0(0 / 0 / 0)$ & $0(0 / 0 / 0)$ & $4(4 / 0 / 0)$ & $0(0 / 0 / 0)$ \\
\hline Crustacea & $6(3 / 3 / 0)$ & $2(0 / 2 / 0)$ & $7(2 / 5 / 0)$ & $2(0 / 2 / 0)$ & $1(0 / 1 / 0)$ & $1(0 / 1 / 0)$ & $6(1 / 5 / 0)$ & $3(0 / 3 / 0)$ \\
\hline Mollusca & $4(1 / 2 / 1)$ & $2(0 / 0 / 2)$ & $4(0 / 3 / 1)$ & $1(0 / 0 / 1)$ & $5(0 / 1 / 4)$ & $4(0 / 0 / 4)$ & $11(0 / 8 / 3)$ & $13(0 / 8 / 5)$ \\
\hline Polychaeta & $13(1 / 3 / 9)$ & $11(0 / 1 / 10)$ & $7(0 / 0 / 7)$ & $6(0 / 0 / 6)$ & $8(0 / 0 / 8)$ & $15(0 / 1 / 14)$ & $8(0 / 0 / 8)$ & $9(0 / 0 / 9)$ \\
\hline Other species & $5(3 / 1 / 1)$ & $2(0 / 0 / 2)$ & $5(0 / 1 / 4)$ & $3(0 / 0 / 3)$ & $1(0 / 0 / 1)$ & $0(0 / 0 / 0)$ & $3(1 / 1 / 1)$ & $1(0 / 1 / 0)$ \\
\hline
\end{tabular}

Numbers of epibiotic, epibenthic and endobenthic species within the dominant taxa are given in parentheses (epibionts/epibenthos/endobenthos) 
Fig. 5 Species-sample curves for mussel beds (left panels) and surrounding sand flats without mussels (right panels) in four regions of the world (see Fig. 2)
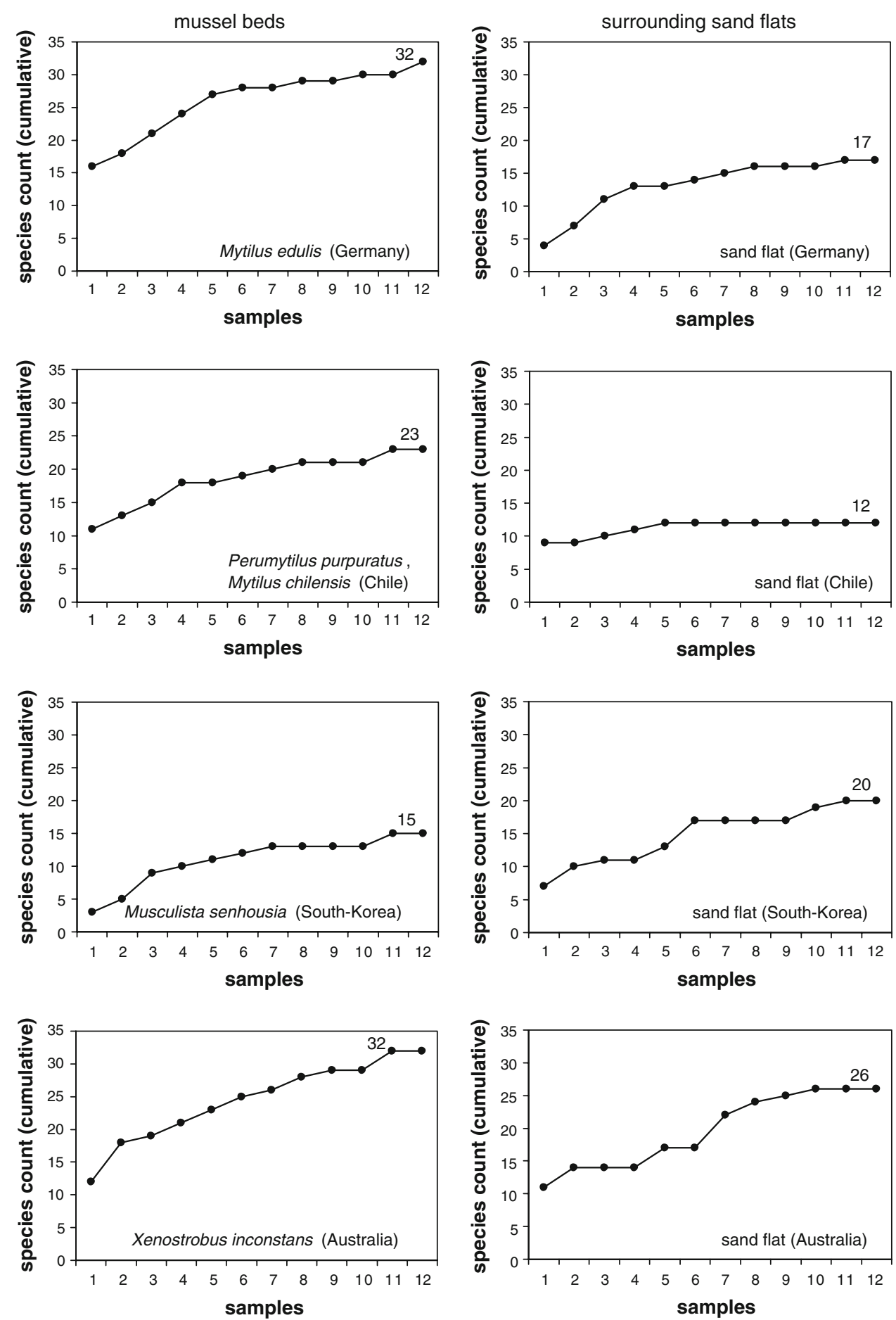

In contrast, in Korean beds of $M$. senhousia, mean species number $(2.6 \pm 1.3$ species per sample) was lower in comparison to samples without mussels $(4.0 \pm 1.8$ species per sample; $t$ test, $P<0.05$ ) while Australian beds of $X$. inconstans showed an increased mean species number $(13.3 \pm 1.4$ species per sample) compared to surrounding tidal flats $(9.4 \pm 2.1$ species per sample; $t$ test, $P<0.0001)$.
Occurrence of epibionts, epibenthic and endobenthic species

Epibionts were not encountered on sand flats because of the lack of epibenthic structures (Fig. 7). The total number of epibenthic species (without epibionts) was similar in mussel beds of Germany (M. edulis) and Chile (mixed P. purpuratus and $M$. chilensis) and much higher than in areas 
Fig. 6 Mean species number per sample $(+\mathrm{SD}, n=12)$ in epibenthic mussel beds (beds of M. edulis in Germany and mixed beds of $P$. purpuratus and M. chilensis in Chile) and endobenthic mussel beds (beds of M. senhousia in South Korea and $X$. inconstans in Australia) in comparison to bare tidal flats without mussel aggregations

Fig. 7 Total numbers of epibionts, epi- and endobenthic species occurring in epibenthic mussel aggregations (M. edulis beds in Germany and mixed $P$. purpuratus and $M$. chilensis beds in Chile) and endobenthic mussel beds (beds of M. senhousia in South Korea and X. inconstans in Australia) in comparison to surrounding bare sand flats
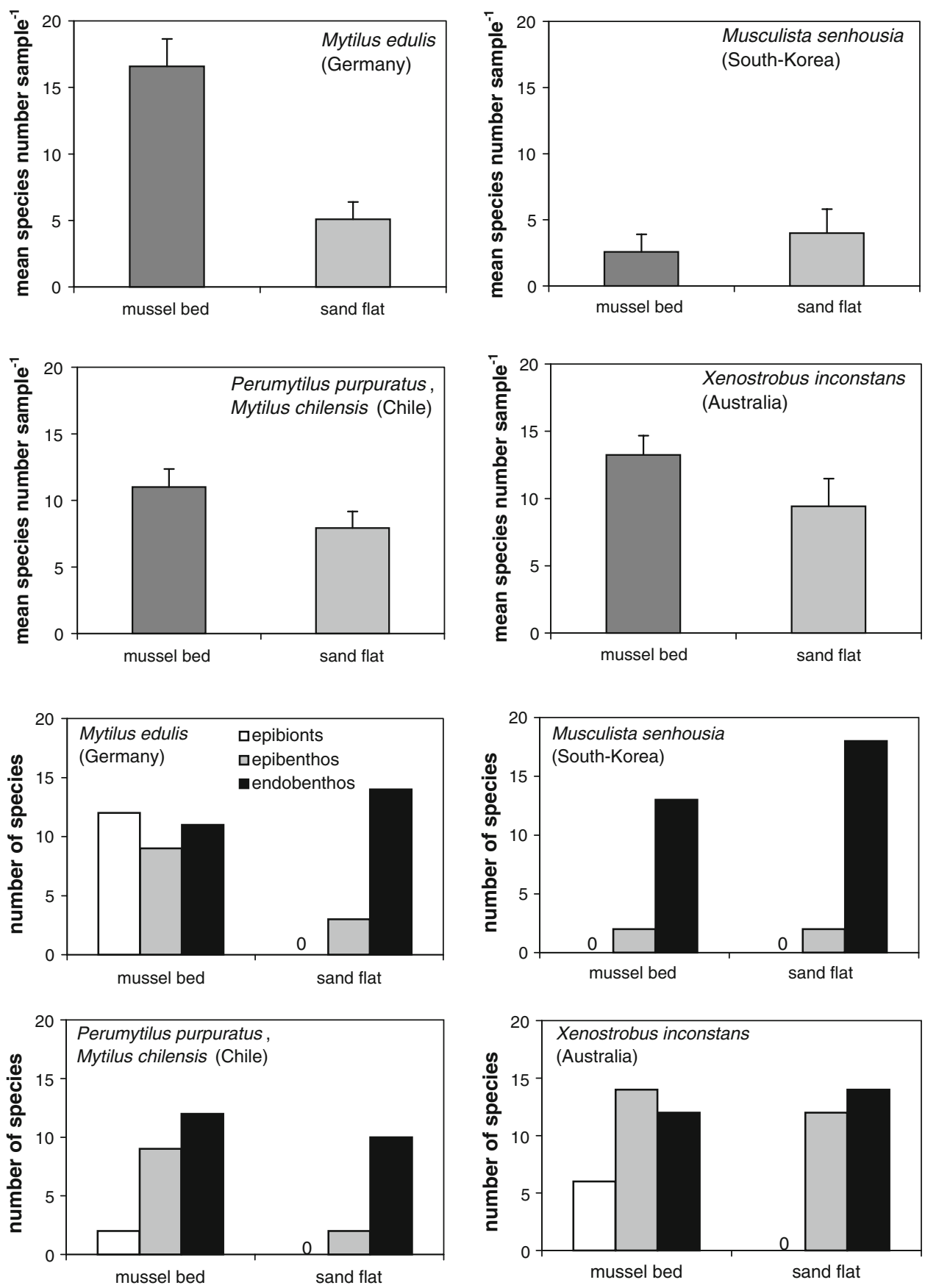

without bivalves. In both systems, the total number of endobenthic species was similar in mussel beds and surrounding sand flats.

In M. senhousia beds (Yellow Sea, South-Korea), no epibiontic species were detected whereas six epibiontic species were identified in X. inconstans beds in Australia. In both South-Korea and Australia, total epibenthic species number was similar in mussel beds and areas without bivalves, although there were many times more of such species in Australia. Total endobenthos species number in M. senhousia beds was lower than in bare sand flats in
South Korea, while number of endobenthic species was similar in X. inconstans beds and sand flats in Australia.

Mean number of epibenthic organisms per sample was significantly higher in mussel beds in Germany and Chile in comparison to areas without mussels $(t$ test, $P<0.0001$, respectively) while no significant differences existed in mean numbers of endobenthic organisms in mussel beds and surrounding sand flats $(t$ test, $P>0.05$, respectively, Fig. 8).

In beds of M. senhousia mean species numbers of epi- and endobenthic organisms showed no significant difference 
Fig. 8 Mean species number per sample $(+\mathrm{SD}, n=12)$ of epibionts, epi- and endobenthic organisms occurring in epibenthic mussel beds (beds of M. edulis in Germany and mixed beds of $P$. purpuratus and M. chilensis in Chile) and endobenthic mussel beds (beds of M. senhousia in South Korea and X. inconstans in Australia) compared to tidal flats without mussel aggregations
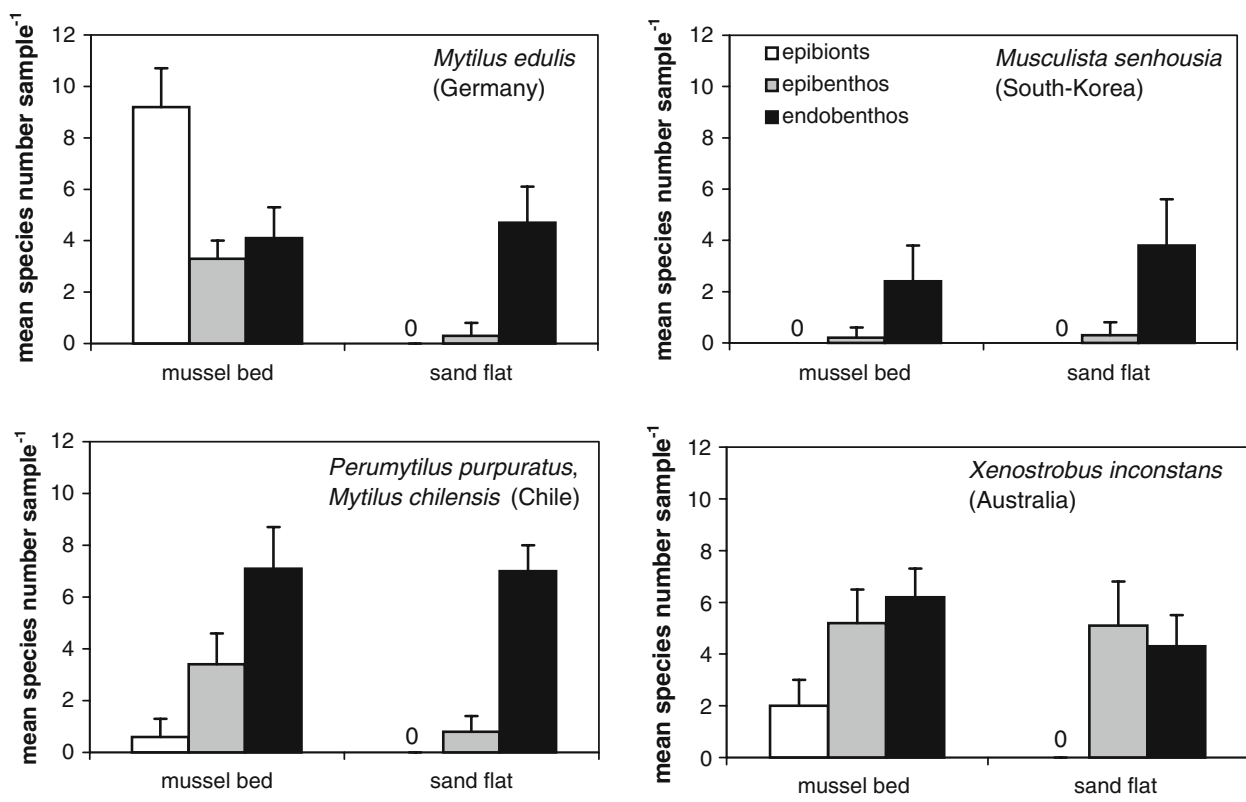

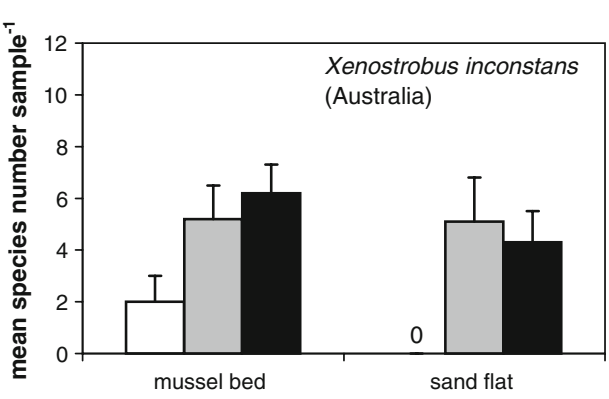

( $t$ test, $P>0.05$, respectively). In addition, there was no difference in mean number of epibenthic species between mussel aggregations and bare tidal areas in Australia ( $t$ test, $P>0.05)$. Mean number of endobenthic species was significantly higher in beds of $X$. inconstans ( $t$ test, $P<0.001$ ).

\section{Discussion}

We investigated the species community of four kinds of soft bottom mussel beds generated by different mytilid species and compared the associated organisms with the species assemblage of surrounding sediments in four sedimentary coastal systems worldwide. We recognize that these four sites are hardly representative for all kinds of mussel beds in sedimentary environments. However, given the scarcity of data sets obtained with the same method, time has not yet come for a comprehensive meta-analysis. Our pioneer approach serves to build hypotheses which may stimulate and direct further studies in the infant field of global coastal ecology.

In all regions, species assemblages within mussel aggregations were different from the community occurring in bare sand flats without mussels, which is concordant with other studies on soft bottom mussel beds (e.g. Ragnarsson and Raffaelli 1999; Commito and Dankers 2001; Duarte et al. 2006). Many species were confined to one habitat type and at least $30 \%$ of total species number found within one study site was restricted to mussel beds. Although soft bottom mussel beds often cover less than $1 \%$ of tidal area in coastal systems (Büttger et al. 2008), they provide an additional habitat with a unique species assemblage that would otherwise not occur. Norling and Kautsky (2007) argue that the physical structure properties of a soft bottom mussel bed are the main factor responsible for biodiversity of associated species and that biological activities may have an additional positive effect on diversity due to the increased supply of mussel deposits and organic matter as a food source. Therefore, ecosystem engineering mytilid mussels may conspicuously enhance biodiversity by increasing habitat heterogeneity in a sedimentary coastal system.

However, when comparing species richness and diversity inside and outside the investigated mussel beds the pattern was variable. Total species number in mussel beds in the North Sea (M. edulis) and at the Chilean coast (P. purpuratus and M. chilensis) were enhanced, but lower in mussel aggregations in the Yellow Sea (M. senhousia) and similar in beds at the south Australian coast (X. inconstans) compared to sand flats without mussels. In contrast to our study, Crooks (1998) found higher species richness inside mats of $M$. senhousia on the North American Pacific coast and Commito et al. (2005) demonstrated a decreased diversity in M. edulis beds in comparison to sand flats without mussels on the North American Atlantic coast. Species richness within mussel beds may be enhanced but also decreased compared to bare sand flats, depending on the respective ecosystem. Thus, diversity of mussel beds seems to be less dependent on mytilid species and the question arises:

When does a soft bottom mussel bed function as hot spot of diversity?

Our investigations included both the associated species assemblage of epibenthic (North Sea, Chilean coast) and endobenthic mussel beds (Yellow Sea, south Australian 
coast). For epibenthic mussel beds, diversity of associated organisms was enhanced, but this was not the case in endobenthic beds.

In sedimentary coastal environments, mussel beds provide the only major hard substratum available, which is especially true for epibenthic beds with most mussels lying on the sediment surface (Dittmann 1990; Albrecht 1998). These are often used by sessile algae and invertebrates, e.g. in mussel beds of M. edulis in the North Sea where we detected a high number of organisms attached to the mussels (12 species). However, in epibenthic beds of M. chilensis and $P$. purpuratus at the Chilean coast, we detected a comparatively low number of epibionts (two species), which was also lower than in endobenthic beds of $X$. inconstans in Australia (six species). This indicates that epibenthic beds are not generally inhabited by a high number of epibiotic species.

In both epibenthic mussel beds investigated, we detected an enriched epibenthos community (mobile species living predominantly on the sediment surface, not including epibionts) compared to surrounding sediments. These organisms may profit from the structural complexity of mussel aggregations on the bottom which provides refuges from competition, predation and disturbance (e.g. Commito and Dankers 2001; Norling and Kautsky 2007). This pattern is consistent with other studies on species diversity in epibenthic mussel beds (Dittmann 1990; Günther 1996) and high species number of epibenthos was clearly responsible for enriched diversity in this mussel bed type. This may lead to the assumption that epibenthic soft bottom mussel beds have a higher diversity than surrounding sand flats and can, therefore, be considered biodiversity hot spots. However, we investigated only two epibenthic beds and the studies by Dittmann (1990) and Günther (1996) supporting this assumption were also performed on M. edulis mussel beds in the North Sea. Thus, further investigations on epibenthic mussel in different coastal systems are necessary. They should include experimentally arranged epi- and endobenthic mussel beds of one mytilid species to enable direct comparisons of diversity within a study area.

That epibenthic mussel beds do not necessarily have a rich associated community is clear from the low numbers of epibionts attached to epibenthic mussel beds on the Chilean coast. Therefore, at the present state of knowledge, a generalisation of the structural function of epibenthic soft bottom mussel beds for associated organisms must be considered tentative.

That mussel beds cannot generally be considered biodiversity centres is supported by our investigations on endobenthic beds in the Yellow Sea and at the south Australian coast. Woodin (1976) predicted that densely packed suspension feeding bivalves may prevent successful larval settlement of associated organisms through intensive filtration activity and ingestion of free swimming larvae. Additionally, she stated that recently settled larvae are suffocated in produced faecal material where conditions for many animals are harmful due to low oxygen and high sulphide concentrations. This would result in decreased species richness and abundance in beds with high mussel densities. In endobenthic mussel beds in Australia, $X$. inconstans attained densities of about 18,000 ind. $\mathrm{m}^{-2}$, which was ninefold higher than in mussel beds of M. senhousia in the Yellow Sea. Despite high mussel densities in Australian beds, total species number of infauna was similar and mean number of infaunal species per sample was about twice as high as that in beds of M. senhousia. Furthermore, associated epi- and endobenthic species numbers in $X$. inconstans beds were similar to surrounding sedimentary areas without mussels, and most of the endobenthic organisms within mussel beds were polychaete worms (Dittmann and Buschbaum in preparation). These results suggest that high mussel densities do not prevent a rich and diverse associated community of infaunal organisms. On the other hand, beds with reduced mussel densities may not be inhabited by a rich associated community, as we have shown for the Yellow Sea. These findings are in concordance with results obtained by Jaramillo et al. (2007) and contradict Woodin's hypothesis which was also questioned by Commito (1987), Commito and Boncavage (1989) and Commito and Dankers (2001).

Hence, the question of whether a mussel bed is highly diverse seems to be less dependent on the mytilid species, the density and epi- versus endobenthic traits.

Site-specific character of soft bottom mussel beds

We suggest that the degree of diversity may depend strongly on the regional spectrum of species and the ability of these species to adapt to the engineered conditions within mussel beds. Soft bottom mussel beds may constitute physically similar habitats throughout the world but the responses of other benthic species may not be the same, and thus the arising mussel bed communities arise by site-specific rules. Future research will need to include the species pools of habitats in the respective regions which are the main sources to the species colonizing mussel beds.

The non-deterministic effects of mussel beds on associated communities may serve as an analogue to the limitations of predicting the effects of alien species invasions. Particularly, mussels have been introduced across oceans many times with both, facilitating and inhibiting effects on species in recipient ecosystems (e.g. Branch and Steffani 2004; Crooks 1998; Crooks and Khim 1999; Rilov et al. 2004; Robinson et al. 2007). Apparently, we cannot derive the effects directly from the properties of mussel species. They unfold their effects by interactions with the respective physical and biotic environment, including feedbacks 
operating over long time scales. In conclusion, our study supports the non-deterministic nature of ecological networks by recognizing a site-specific pattern in mussel bed communities over the world.

Acknowledgments We thank many highly motivated students for their assistance and kindness. In all visited countries, they gave us the feeling of being at home. We are grateful to Yane and Anke Dreeskamp for field assistance. Tony Chapman, Peter Herman and Tom Ysebaert gave valuable comments on the manuscript. Tobias Dolch helped with preparation the figures. Research of this study was supported by the German Research Foundation (project number 446 KOR 113/163), the Korea Science and Engineering Foundation (project number F01-2002-000-200330-0), the international bureau of the BMBF (project number CHL 01/021) and CONICYT (project number $\mathrm{N}$ 2001-182). A visiting scholarship to C. Buschbaum was provided by the Flinders Research Centre for Coastal and Catchment Environments (FR3cE, Adelaide, Australia). The project was carried out within the framework of the MarBEF Network of Excellence 'Marine Biodiversity and Ecosystem Functioning' which is funded by the Sustainable Development, Global Change and Ecosystems Programme of the European Community's Sixth Framework Programme (contract no. GOCE-CT-2003-505446). This publication is contribution number MPS-08030 of MarBEF.

\section{References}

Albrecht AS (1998) Soft bottom versus hard rock: community ecology of macroalgae on intertidal mussel beds in the Wadden Sea. J Exp Mar Biol Ecol 229:85-109

Albrecht A, Reise K (1994) Effects of Fucus vesiculosus covering intertidal mussel beds in the Wadden Sea. Helgol Meeresunters 48:243-256

Asmus H (1987) Secondary production of an intertidal mussel bed community related to its storage and turnover compartments. Mar Ecol Prog Ser 39:251-266

Branch GM, Steffani CN (2004) Can we predict the effects of alien species? A case-history of the invasion of South Africa by Mytilus galloprovincialis (Lamarck). J Exp Mar Biol Ecol 300:189-215

Büttger H, Asmus H, Asmus R, Buschbaum C, Dittmann S, Nehls G (2008) Community dynamics of intertidal soft-bottom mussel beds over two decades. Helgol Mar Res 62:23-36

Buschbaum C, Saier B (2001) Growth of the mussel Mytilus edulis L. in the Wadden Sea affected by tidal emergence and barnacle epibionts. J Sea Res 45:27-36

Borthagaray AI, Carranza A (2007) Mussels as ecosystem engineers: their contribution to species richness in a rocky littoral community. Acta Oecol 31:243-250

Clarke KR, Warwick RH (2001) Change in marine communities: an approach to statistical analysis and interpretation, 2nd edn. PRIMER-E Ltd, Plymouth

Commito JA (1987) Adult-larval interactions: predictions, mussels and cocoons. Estuar Coast Shelf Sci 25:599-606

Commito JA, Boncavage EM (1989) Suspension-feeders and coexisting infauna: an enhancement counterexample. J Exp Mar Biol Ecol 125:33-42

Commito JA, Dankers NMJA (2001) Dynamics of spatial and temporal complexity in European and North American soft-bottom mussel beds. In: Reise K (ed) Ecological comparisons of sedimentary shores. Springer, Berlin, pp 39-59

Commito JA, Celano EA, Celico HJ, Como S, Johnson CP (2005) Mussels matter: postlarval dispersal dynamics altered by a spatially complex ecosystem engineer. J Exp Mar Biol Ecol 316:133-147
Crooks JA (1996) The population ecology of an exotic mussel, Musculista senhousia, in a southern California bay. Estuaries 19(1):4250

Crooks JA (1998) Habitat alteration and community-level effects of an exotic mussel, Musculista senhousia. Mar Ecol Prog Ser 162:137-152

Crooks AJ (2002) Characterizing ecosystem-level consequences of biological invasions: the role of ecosystem engineers. Oikos 97:153-166

Crooks JA, Khim HS (1999) Architectural vs. biological effects of a habitat-altering exotic mussel, Musculista senhousia. J Exp Mar Biol Ecol 240:53-75

Dittmann S (1990) Mussel beds-amensalism or amelioration for intertidal fauna? Helgol Meeresunters 44:335-352

Dittmann S (2007) Soft sediments. In: Connell SD, Gillanders Bm (eds) Marine ecology. Oxford University Press, Oxford, pp 428449

Duarte C, Jaramillo E, Contreras H, Figueroa L (2006) Community structure of the macroinfauna in the sediments below an intertidal mussel bed (Mytilus chilensis (Hupe)) of southern Chile. Rev Chil Hist Nat 79:353-368

Edgar JE (2000) Australien marine life: the plants and animals of temperate waters. Reed New Holland, Sydney

Gätje C, Reise K (1998) Ökosystem Wattenmeer, Austausch-, Transport- und Stoffumwandlungsprozesse. Springer, Berlin

Gebauer P, Paschke K, Moreno CA (2007) Reproductive biology and population parameters of Petrolisthes laevigatus (Anomura: Porcellanidae) in southern Chile: consequences on recruitment. J Mar Biol Assoc UK 87:729-734

Günther CP (1996) Development of small Mytilus beds and its effects on resident intertidal macrofauna. Mar Ecol 17(1-3):117-130

Gutiérrez JL, Jones CG, Strayer DL, Iribarne OO (2003) Mollusks as ecosystem engineers: the role of shell production in aquatic habitats. Oikos 101:71-81

Jaramillo E, Contreras H, Duarte C (2007) Community structure of the macroinfauna inhabiting tidal flats characterized by the presence of different species of burrowing bivalves in Southern Chile. Hydrobiologia 580:85-96

Jones CG, Lawton JH, Shachak M (1994) Organisms as ecosystem engineers. Oikos 69:373-386

Jones CG, Lawton JH, Shachak M (1997) Positive and negative effects of organisms as physical ecosystem engineers. Ecology 78(7): 1946-1957

Lintas C, Seed R (1994) Spatial variation in the fauna associated with Mytilus edulis on a wave-exposed rocky shore. J Moll Stud 60:165-174

Morton B (1974) Some aspects of the biology, population dynamics, and functional morphology of Musculista senhousia Benson (Bivalvia, Mytilidae). Pac Sci 28:19-33

Morton B (1992) The evolution and success of the heteromyarian form in the Mytiloida. In: Gosling E (ed) The mussel Mytilus: ecology, physiology genetics and culture. Elsevier, Amsterdam, pp 21-52

Norling P, Kautsky N (2007) Structural and functional effects of Mytilus edulis on diversity of associated species and ecosystem functioning. Mar Ecol Prog Ser 351:163-175

Ong Che RG, Morton B (1992) Structure and seasonal variations in abundance of the macro-invertebrate community associated with Septifer virgatus (Bivalvia: Mytilidae) at Cape D'Aguilar, Hong Kong. Asian Mar Biol 9:217-233

Peake AJ, Quinn GP (1993) Temporal variation in species-area curves for invertebrates in clumps of an intertidal mussel. Ecography 16:269-277

Ragnarsson SÁ, Raffaelli D (1999) Effects of the mussel Mytilus edulis L. on the invertebrate fauna of sediments. J Exp Mar Biol Ecol 241:31-43

Reise K (1985) Tidal flat ecology. Springer, Heidelberg 
Reusch TBH, Williams SL (1998) Variable response of native eelgrass Zostera marina to a non-indigenous bivalve Musculista senhousia. Oecologia 113:428-441

Rilov G, Benayahu Y, Gasith A (2004) Prolonged lag in population outbreak of an invasive mussel: a shifting-habitat model. Biol Invasions 6:347-364

Robinson TB, Branch GM, Griffiths CL, Govender A, Hockey PAR (2007) Effects of the invasive mussel Mytilus galloprovincialis on rocky intertidal community structure in South Africa. Mar Ecol Prog Ser 340:163-171

Seed R (1996) Patterns of biodiversity in the macro-invertebrate fauna associated with mussel patches on rocky shores. J Mar Biol Assoc UK 76:203-210

Seed R, Suchanek TH (1992) Population and community ecology of Mytilus. In: Gosling E (ed) The mussel Mytilus: ecology, physiology genetics and culture. Elsevier, Amsterdam, pp 87-169

Smith JR, Fong P, Ambrose RF (2006) Dramatic declines in mussel bed community diversity: response to climate change? Ecology 87(5):1153-1161

Suchanek TH (1986) Mussels and their role in structuring rocky shore communities. In: Moore PG, Seed R (eds) The ecology of rocky coasts. Columbia University Press, New York, pp 70-96

Suchanek TH (1992) Extreme biodiversity in the marine environment: mussel bed communities of Mytilus californianus. Northwest Environ J 8:150-152
Thiel M, Ullrich N (2002) Hard rock versus soft bottom: the fauna associated with intertidal mussel beds on hard bottoms along the coast of Chile, and considerations on the functional role of mussel beds. Helgol Mar Res 56:21-30

Tokeshi M (1995) Polychaete abundance and dispersion patterns in mussel beds: a non-trivial 'infaunal' assemblage on a pacific south American rocky shore. Mar Ecol Prog Ser 125:137-147

Tokeshi M, Romero L (1995) Filling a gap: dynamics of space occupancy on a mussel-dominated subtropical rocky shore. Mar Ecol Prog Ser 119:167-176

Tsuchiya M, Nishihira M (1985) Islands of Mytilus as a habitat for small intertidal animals: effect of island size on community structure. Mar Ecol Prog Ser 25:71-81

Tsuchiya M, Nishihira M (1986) Islands of Mytilus edulis as a habitat for small intertidal animals: effect of Mytilus age structure on the species composition of the associated fauna and community organization. Mar Ecol Prog Ser 31:171-187

Valdivia N, Thiel M (2006) Effects of point-source nutrient addition and mussel removal on epibiotic assemblages in Perumytilus purpuratus beds. J Sea Res 56:271-283

Woodin SA (1976) Adult-larval interactions in dense infaunal assemblages: patterns of abundance. J Mar Res 34:25-41

Womersley HBS, Edmonds SJ (1958) A general account of the intertidal ecology of south Australian coasts. Aust J Mar Freshw Res 9(2):217-260 